\title{
Thickener modelling - from laboratory experiments to full-scale prediction of what comes out the bottom and how fast
}

\author{
PJ Scales University of Melbourne, Australia \\ AH Crust University of Melbourne, Australia \\ SP Usher University of Melbourne, Australia
}

\begin{abstract}
Predicting full-scale thickener performance, including the solids flux and concentration delivered from a thickener underflow based solely on laboratory-scale experiments, has long been the holy grail of thickener design and operation. A number of researchers have developed both thickener models and laboratory characterisation techniques to measure sedimentation and compressional properties of flocculated suspensions. Combining these to produce predictions of actual performance generally results in an under-estimation of the thickener solids flux, often by a factor of between 10 and 20. Consequently, a range of empirical methods and industry scalars has been developed to get around this discrepancy.
\end{abstract}

Analysis of the reasons for the discrepancy shows that changes in aggregate structure in shear, due to inter-aggregate buffeting and shear induced by collisions with surfaces and rakes, causes the flocculated aggregate to change from a fractal to a denser non-fractal object as it progresses through the thickener. These changes are shear rate and solids concentration dependent and as such, very difficult to reproduce in the laboratory and then incorporate into thickener models.

A method to quantify the time and shear rate dependent changes in aggregate structure is now available and a model has been developed that allows incorporation of this effect into modelling. The change in aggregate behaviour is incorporated through a shear rate dependent densification rate and final extent of aggregate densification. The latter parameter helps to define an upper limit in solids flux behaviour for a given solids underflow concentration. Using the new information, thickener models now predict a range of underflow solids flux outcomes between the upper (densified aggregate) and lower (undensified aggregate) limit for a particular underflow solids concentration, depending on the operational conditions. The difference in underflow solids flux between these two limits is significant and the actual outcome depends on the shear rate and time of shear, as well as total solids residence time in the thickener.

The data indicate that for non-segregating flocculated suspensions, operational conditions that produce the optimum thickener underflow solids flux for a given flocculation condition can now be explored quantitatively without resorting to extensive pilot trials.

\section{$1 \quad$ Introduction}

Thickeners are critically important to the minerals industry. In plan view, they are simple looking devices that should be easy enough to model and design based on the material properties of the feed suspension, a knowledge of the thickener dimensions and the feed flow rate. To consider what needs to be taken into account in such a model, in continuous operation, feed slurry enters through a pipe or launder into a central feedwell, in which flocculation is achieved and much of the momentum/energy of the feed is dissipated. On discharge from the feedwell, the solids are concentrated through sedimentation, hindered sedimentation and then consolidation in a networked solids bed, with thickened slurry then exiting through a discharge or underflow point at the base. The latter is ideally controlled to a fixed slurry rheology to allow predictable disposal in a tailings emplacement (Sofra \& Boger 2002). The liquor released through the phase 
separation process rises and a low solids overflow exits via a weir at the top of the thickener. Despite extensive effort, the holy grail of predicting full-scale thickener performance, including the solids flux and concentration delivered from a thickener underflow, based solely on laboratory-scale experiments, still eludes us (Fawell et al. 2009).

The reason why thickeners are hard to model is nominally because of flocculation. Indeed, for unflocculated and non-segregating feeds to a thickener, prediction of thickener throughput is reasonably straight forward. However, most unflocculated feeds settle very slowly, overflow clarity is poor and thickener throughput to achieve a given underflow solids concentration is low. The industry has an aim of improving the throughput through a given device whilst at the same time still achieving high overflow clarity and the desired underflow rheology or solids concentration. The use of flocculant is critical to this end as it promotes the aggregation of fine particles and enhances the sedimentation rate, in some instances by an order of magnitude in the free settling region. Since thickeners are rate limited devices, the best way to enhance throughput is via improved sedimentation.

For all benefits there is nearly always a trade-off and in the case of flocculation, it is at the expense of the potential underflow solids concentration, since the addition of flocculants produces a stronger aggregate network. Flocculant dosing lowers the output solids for a fixed underflow slurry rheology. The rate limitation of thickening is nonetheless an important consideration here and in the trade-off between (a) the benefits of the addition of flocculant to improve sedimentation, and (b) the reduction in the maximum possible underflow solids concentration due to enhanced network strength, the former is a major and the latter a minor limitation to enhanced throughput.

Understanding and being able to predict the expected size and density of aggregates and, hence, the sedimentation rate of a flocculated suspension that will exit the feedwell of a thickener is therefore an important first step in being able to predict the rate of thickening. This is a non-trivial task (Task 1 ) and the first of one of three major challenges that will be presented herein to the accurate modelling of the thickening process, inclusive of the rate and extent of thickening.

\section{Challenges in thickener throughput prediction}

\subsection{Prediction of aggregate size and density in a thickener}

Research and industrial-scale testing over the past 20+ years has made a significant contribution to resolving Task 1 and whilst work is ongoing, the major issues have been identified and a method that details the role of flocculant mixing, material characteristics on flocculant adsorption, flocculation shear rate and time of exposure to shear on aggregate formation is now well described (Heath et al. 2006; Owen et al. 2008). In addition and just as important, the incorporation of this understanding into a population balance model of flocculation and implementation in phenomenological descriptions of a range of feedwells has been achieved, the latter through computational fluid dynamics (CFD) modelling. This allows prediction of the size and density distribution of aggregates exiting a feedwell for a range of flow and feed/flocculation conditions (Heath et al. 2006; Fawell et al. 2009). This in its own right has been a significant contributor to improved throughput in thickeners.

\subsection{Prediction of thickener throughput}

The second challenge (Task 2) in predicting the rate and extent of thickening is to have a dewatering theory that is able to capture the sedimentation and consolidation response of flocculated aggregates. Such aggregates form a networked bed of particles at the base of the thickener that is compressional. In short, the bed changes in the rate and extent of dewatering depending on the self-weight of the particles in the network. In the case of pressure driven processes such as filtration, the degree of compression and output solids varies with the applied pressure. Traditional models of thickeners did not take the compressional characteristics of flocculated aggregates into account. In addition, laboratory testing of flocculated 
suspensions did not take into account the role of compression in the extraction of dewatering parameters used as inputs into the dewatering theory that is central to the phenomenological models of thickening.

The origin of gravity thickening theory can be traced back to Coe and Clevenger (1916), who observed that the settling rate was dependent on the solids concentration. They postulated the existence of distinct sedimentation and consolidation zones, but were unable to correctly model the physics of consolidation. Kynch provided the next breakthrough in suspension dewatering theory (Kynch 1952). His work developed a method from which the solids flux over a range of solids concentrations could be determined via sediment interface height versus time data from a single laboratory batch settling experiment. Though the data from the Kynch method is useful, it assumes that the networked bed in the sedimentation test is incompressible, which is known to be incorrect for polymer-flocculated suspensions. This restricts the use of the technique in both the extraction of dewatering parameters and in thickener throughput and output prediction, to a condition known as the fan limit (Lester et al. 2005). This is the point where compression of the networked bed of aggregates starts to affect the rate of water escape from a suspension.

Although a unified theory that combined both sedimentation and consolidation was still elusive, the compressive yield capacity of a networked suspension was correctly described in the work of Gibson et al. (1967) and Michaels and Bolger (1962). The compression theory of Michaels and Bolger was updated by Fitch $(1966,1971)$.

A unified theory was eventually developed by Buscall and White (1987) in which they established the fundamental attributes that determine the overall dewaterability of an aggregated suspension as being:

- the gel point (the solids concentration where the aggregated suspension first forms a network); and

- the variation of permeability and compressibility with solids concentration.

The unified theory, inclusive of networked bed consolidation, has now been applied to a large range of dewatering simulations (Auzerais et al. 1990; Howells et al. 1990; Bergstrom et al. 1992; Bürger \& Wedland 1998; Bustos et al. 1999; Karl 1999; Diehl 2000; Bürger et al. 2001). In some cases this was for a continuous thickener (Landman et al. 1988; Usher \& Scales 2005; Lester et al. 2010). Diehl (2000) and Bustos et al. (1999) also looked at thickening of incompressible suspensions, although this is of no interest here. A typical output of a thickener model for a range of networked bed height conditions for a flocculated suspension is shown in Figure 1.

Dewatering theory along with phenomenological thickener dewatering models has been successful in describing dewatering trends in thickeners. This has led to the development of analytical laboratory based tools to generate dewatering parameters relevant to the modelling of thickening at an industrial-scale (Landman et al. 1995; de Kretser et al. 2001; Usher et al. 2001; Lester et al. 2005). Methods for dewatering parameter extraction followed by modelling of thickener performance are now freely available. Based on this overview, one could be fooled into believing that Task 2 was complete and we can now take the outputs of Task 1, use them to allow appropriate laboratory-scale experimentation to extract dewatering parameters for a flocculation condition equivalent to aggregates exiting a feedwell and thus predict thickener performance in a rigorous manner.

Comparison of the predictions from these models with industrial-scale data has shown discrepancies that suggest flaws in the dewatering model (Usher \& Scales 2005). Current industrial practice is to use scalars and empiricism, euphemistically called a 'performance enhancement factor' (PEF) (Gladman et al. 2010). The (PEF) correlates the observed solids flux through a thickener to the predicted flux, at a given underflow solids concentration condition. The observation for flocculated suspensions is that field based devices consistently outperform model predictions based on dewatering parameters extracted from simple laboratory batch settling tests, i.e. the PEF is $>1$. Values for the PEF typically lie between five and 20 (Usher \& Scales 2005). The use of an empirical factor to describe an un-quantified parameter is highly unsatisfactory, as it clearly does not aid the predictive capacity that theoreticians and practitioners alike may wish to achieve through modelling of thickeners. 


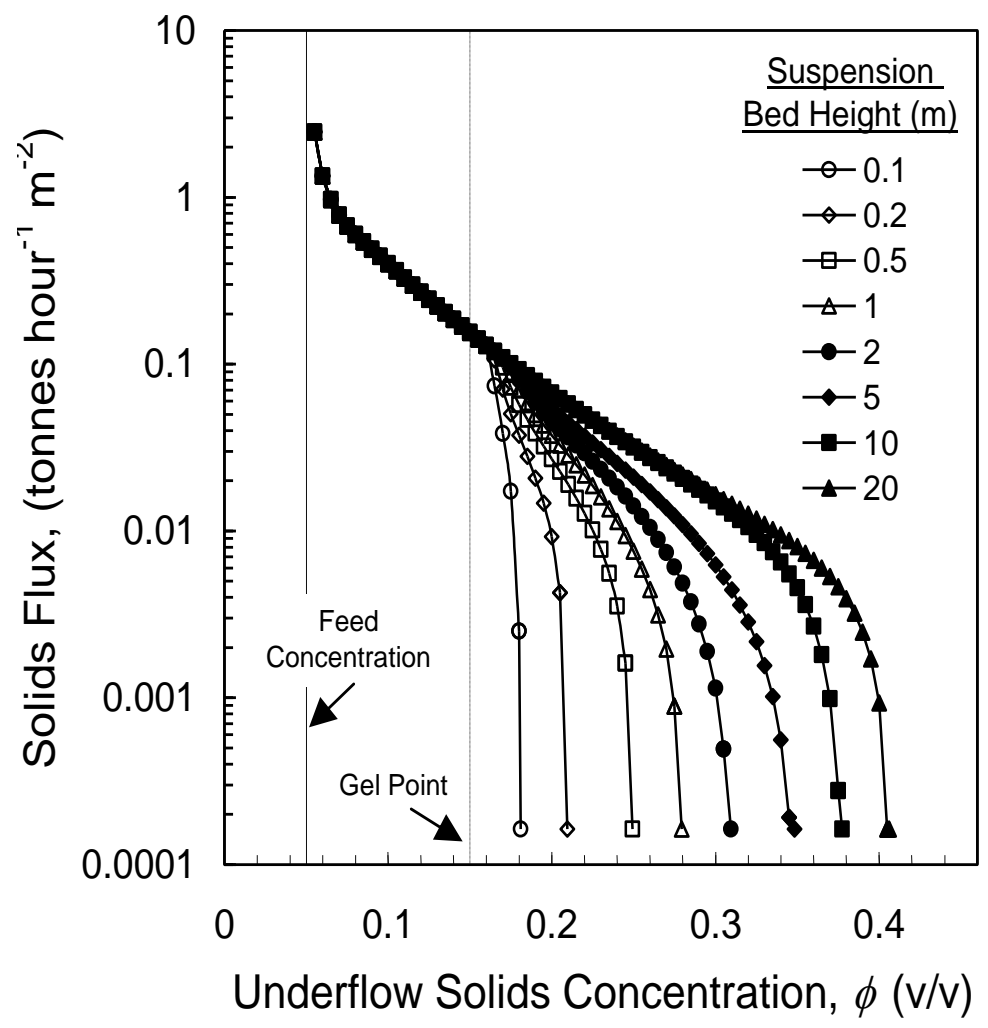

Figure 1 An example of the output of a phenomenological steady state one-dimensional model of thickening (Usher \& Scales 2005) of a flocculated slurry for a range of networked bed heights

So which out of the theory, the model and the dewatering parameter extraction techniques is incorrect in these applications? A simple test is to consider the case of an alternative dewatering device. Analysis for a flocculated suspension of particles where the suspension is fed to a plate and frame filter shows that the same theory, linked to a phenomenological model of filtration, is able to predict dewatering accurately (Stickland et al. 2008). This implies that it is not the theory but either the model or the inputs to the model that is likely to be the cause of the issue. Further analysis shows that using the model for unflocculated suspensions in thickening is accurate and requires no empirical adjustments.

\subsection{The role of shear in thickening}

A simple insight into the issue is provided by several studies that look at gentle stirring of a flocculated sediment. Relative to conventional settling in the absence of shear, the gently stirred case results in considerable enhancement in dewaterability (Comings et al. 1954; Scott 1970; Vesilind \& Jones 1993; van Deventer et al. 2011). Researchers at the University of Melbourne have spent almost ten years characterising the nature of the enhancement and how it can be subsequently incorporated into thickener modelling. The third challenge (Task 3 ) is to understand and then incorporate shear effects associated with flocculated aggregates into thickener modelling.

Shear processes in full-scale thickeners are ubiquitous, since nearly all thickeners have a raking mechanism and the delivery of aggregates from the feedwell is a high shear, albeit energy dissipative process. Traditionally, rakes were designed to transport material to the discharge point, as it is important that a continuous supply of sediment makes its way to the underflow in order to prevent both caking (locally high solids concentrations) and channel formation. However, it is known that raking also plays a role in enhancing dewatering by applying shear (Farrow et al. 2000). Many thickeners also employ dewatering rods that penetrate into the body of the thickener to aid the process, although the design basis for these devices appears to be quite empirical. 
When shear is applied through a mechanical force, such as a rake or through buffeting of aggregates in sedimentation, the expectation is that the local pressure gradients produced will result in the expulsion of water from the flocculated aggregates and subsequent aggregate densification. Research shows that the application of shear is non-trivial, since too much shear breaks up the aggregate structure and is detrimental, and below this level the effect is to turn the essentially fractal flocculated aggregate into a non-fractal but denser entity. This not only enhances the free settling rate of these aggregates but the hindered settling rate as well (Gladman et al. 2005). In addition, the aggregates pack more effectively and have a higher gel point. In terms of thickener operation, a number of other elements that have been quantified in the laboratory are noteworthy:

1. Aggregate densification as a result of shear is not limited to the networked bed zone of a thickener. This is an important observation and indicates that the process is driven by inter-aggregate collisions as much as the effect of shear on an individual aggregate (Spehar et al. 2015) and forms the basis of the Outotec SET process (Loan \& Arbuthnot 2010).

2. The aggregate densification rate constant is of the order $10^{-5}$ to $10^{-3} \mathrm{~s}^{-1}$ and is affected by the shear rate (Spehar et al. 2015). Given that the process is not instantaneous and it is difficult to mix the entire thickener simultaneously, the residence time in the thickener and the amount of time a given aggregate is exposed to shear is important to the end result. Of note is that the residence time of an aggregate in many industrial thickeners we have studied is of order 2-4 hours, consistent with the inverse of the rate constant. This implies that in the absence of shear processes, it is possible that an aggregate would not be optimally densified in the time-scale of thickening.

3. The extent of aggregate densification is quite insensitive to the shear rate, provided the shear rate is less than $10 \mathrm{~s}^{-1}$. This makes modelling easier and further hints at the drivers of the densification process, namely that the predicted pressure in front of a raking element is weakly sensitive to shear and strongly sensitive to the solids concentration (i.e. the number of aggregates per unit volume). In short, buffeting of aggregates is a critical driver to the rate and extent of densification (Spehar 2014). The shear rate of many raking systems in thickeners is predicted to be less than $10 \mathrm{~s}^{-1}$ (Rudman et al. 2008).

4. The change in aggregate diameter as a result of densification is measured to be of order $15-25 \%$ (Spehar et al. 2015).

5. The role of sloped surfaces is a significant source of aggregate interaction such that just like in the case of gentle stirring, a suspensions settles further and faster in a vessel with sloped walls (Usher and Scales 2009).

\subsubsection{Dewatering parameter measurement in the laboratory}

There are two methods that have been developed to extract the aggregate densification parameters that describe the rate and extent of densification that in turn lead to significant enhancements in thickener performance. One of these is from raked settling tests in the laboratory. A four-pronged rake is rotated slowly in a standard batch settling test. The settling interface is tracked in the presence and absence of shear and the settling curve analysed using a modified Kynch approach (Kynch 1952; van Deventer et al. 2011) assuming that the aggregates that are settling are changing in time. This analysis is restricted to the zone of settling where compressional effects are unimportant, but the long term behaviour of the test is also monitored to give the maximum extent of aggregate densification. The rate and extent of aggregation are then extracted assuming the densification process follows the form (van Deventer et al. 2011): 


$$
\frac{d D_{a g g}}{d t}=A\left(D_{a g g} \quad D_{a g g}\right)
$$

Where:

$$
\begin{aligned}
& A=\text { a proportionality constant (or rate parameter) with units of } \mathrm{s}^{-1} . \\
& D_{a g g}=\text { the diameter of the flocculated aggregate. } \\
& D_{a g g \infty}=\text { the final size of the aggregate. }
\end{aligned}
$$

This allows data to be extracted from a relatively straight forward laboratory test.

The functional form described in Equation 1 is empirical but is able to fit data from a more complicated but easier to analyse laboratory test. The fitting of batch sedimentation data is based on the assumption that any point down the settling curve can be associated with an iso-concentration line. These concentrations change as the settling test proceeds. Another approach is to hold the suspension concentration constant through fluidisation of the settling test and examine the upward velocity change required to maintain an interface at a constant level. The test in question is described in detail in a recent publication (Spehar et al. 2015). The change in velocity can be related directly to a change in aggregate diameter (assuming no aggregate breakage). A typical dataset for a flocculated suspension at a fixed shear rate is shown in Figure 2. Performing either the fluidisation or raked settling test across a range of shear conditions allows development of a densification rate constant versus shear rate (or rpm) curve. Data for a set of sedimentation tests are shown in Figure 3. The data show an increase in rate with increasing shear followed by a plateau region. It is assumed that higher shear rates will cause aggregate breakup and decrease the settling rate, although this is hard to characterise since the settling interface becomes cloudy upon aggregate breakup.

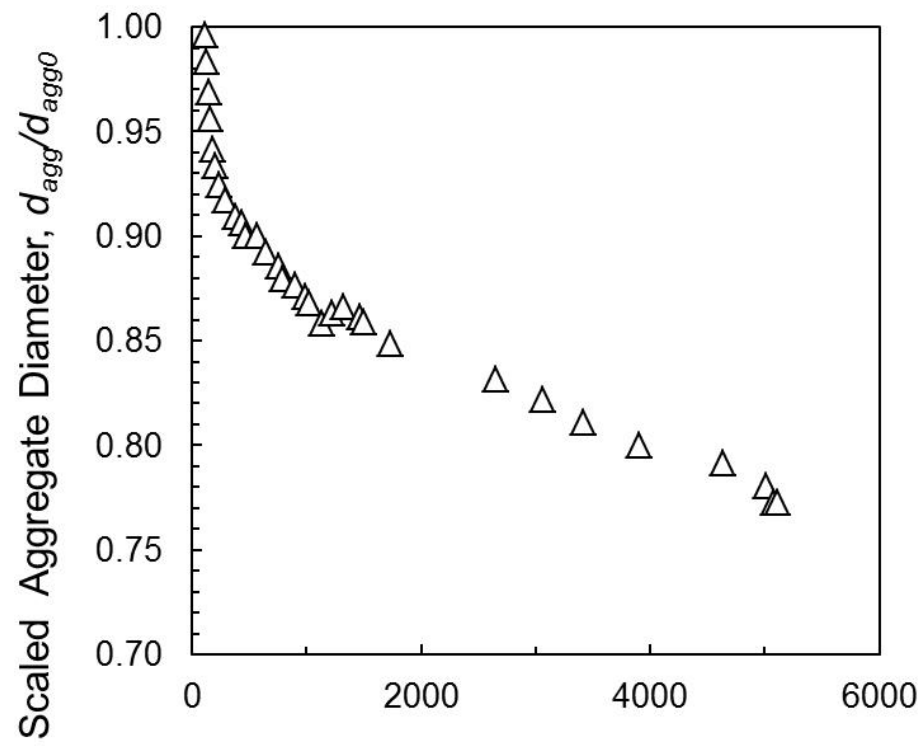

Fluidisation Time, $t(s)$

Figure 2 Change in aggregate size as a function of time for a flocculated calcium carbonate suspension in a fluidised bed reactor, rotating at a rate of $1.6 \mathrm{rpm}$. The vertical axis is presented in terms of ratio of the aggregate size to the aggregate size at the start of the test. The settling rate improves with fluidisation time. Detailed method presented in Spehar et al. (2015) 


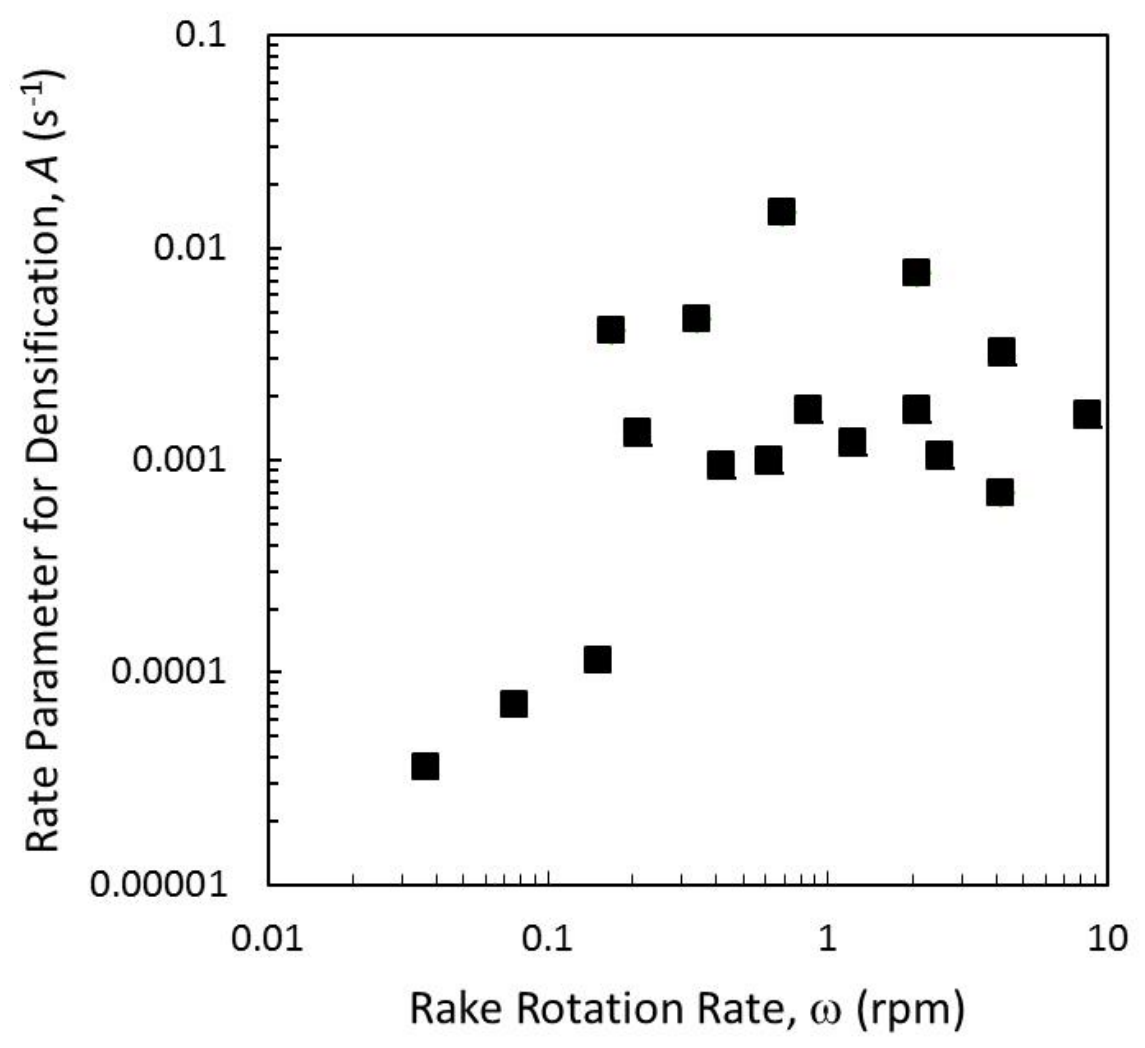

Figure 3 Rate of densification, $A,\left(s^{-1}\right)$, as a function of shear rate for a flocculated calcium carbonate suspension in a raked batch sedimentation test. The data were extracted using the method described in another publication (van Deventer et al. 2011)

\subsubsection{Thickener modelling with aggregate densification}

A steady state phenomenological thickener model incorporating aggregate densification was developed by Usher et al. (2009). This model was able to show the expected limits of operational behaviour but provided no transient insights, such as whether it might be better to rake in the hindered zone or in the networked bed zone of a thickener. The first attempt at such a model was presented not long before publication of this paper (Zhang et al. 2013; Grassia et al. 2014), although it is not yet in a form where practitioners might see it as useful. The most practical aspect of the exercise to date, is that with a knowledge of the expected extent of aggregate densification, something that can be obtained quite quickly using a simple raking test in the laboratory, the maximum throughput of a thickener can be inferred. Given that these tests imply a $15-25 \%$ change in aggregate diameter, the predicted change in throughput is shown to be a PEF of the order of 20. This correlates quite well with observed discrepancies between models in the absence of shear and normal thickener practice and hints, that for the first time, prediction of thickener throughput performance based on laboratory experiments looks viable. An example of the output of the steady state model is shown in Figure 4. In this instance, the predicted throughput enhancement based on a change in aggregate diameter of $20 \%$ is shown to be of order 16 . 


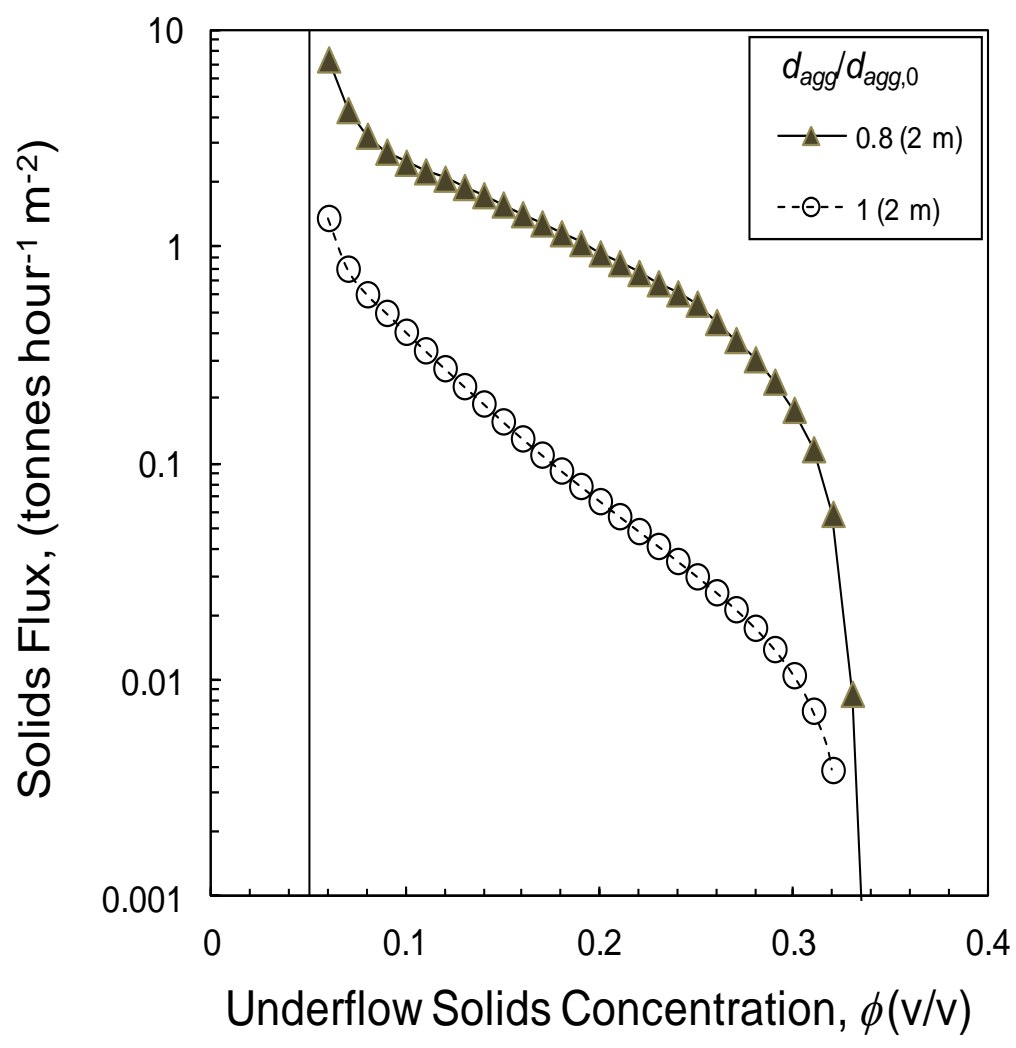

Figure 4 Prediction of the thickener model of Usher et al. (2009) for an aggregate densification scenario whereby the change in aggregate diameter is $20 \%$

It is now appropriate to sum up the state of play on Task 3. It has been demonstrated that models and laboratory methods now exist to incorporate the most important effect of shear on thickener throughput, namely shear induced aggregate densification. The rate and extent of densification have been shown to demonstrate a peaked behaviour as a function of shear rate and if this transient behaviour could be incorporated into modelling, the last key step in the modelling prediction envelope would be in place. This is indeed the case, although the numerical processes are still cumbersome and work is required to make the process industry friendly. An interesting conclusion nonetheless is that if there is sufficient shear and the time duration is such that the final predicted aggregate size is reached within the thickener, then the transients are unimportant other than to determine the optimum point of shear in the thickener. If this is the case, then the steady state model (Usher et al. 2009) is sufficient to predict throughput.

\section{Thickener output prediction}

The steady state thickener model outputs shown in Figure 4 for flocculated aggregates do not provide an indication of the expected underflow solids concentration other than that each solids concentration is linked to a solids flux into the thickener. In practice however, just as thickeners are permeability limited, they are also rake torque limited. This implies that the best indication of the expected solids output of the thickener comes from a knowledge of the yield stress versus solids curve for the suspension being processed, matched to the predicted rake torque for that yield stress. Correlations of the yield stress of a suspension to rake torque have been developed and input to CFD models of rakes (Rudman et al. 2008). The relationship to the rheology of the suspension is found to be highly predictable. The conclusions of the work were quite clear, namely:

"Rake torque is a key issue in thickener operation and it was found that the yield stress of the suspension is the major factor in determining rake torque. Over a range of rake speeds, the measured torque was an almost linear function of yield stress." (Rudman et al. 2008) 
Based on this analysis, a vertical line drawn on Figure 4, starting at the concentration corresponding to the preferred operational torque of the rake in the thickener, converted to a yield stress and thence to a concentration, will intersect the model curve at the expected throughput of the thickener. On this basis, a yield stress versus concentration plot for the flocculated suspension is an essential tool in the prediction of the solids output and solids throughput of a thickener.

\section{$4 \quad$ Conclusions}

Thickener modelling is demonstrated to be a science that is heavily reliant on a knowledge of the state of flocculation of aggregates leaving the feedwell of a thickener, as well as measurements of the sedimentation behaviour and response to gentle shear of these same aggregates. It is shown that with this knowledge and that of the yield stress of a suspension of the said aggregates as a function of concentration, steady state thickener modelling incorporating aggregate densification is able to predict the maximum throughput to achieve a fixed solids concentration. Correlation with field studies show the predictions to be of the right order. In the presence of uniform raking and an adequate residence time, the need for transient modelling of the behaviour, which is likely to provide insights into the optimum point in the thickener to effect shear, is shown to be an advanced option that may not be needed to predict thickener performance in terms of what comes out the bottom and how fast. The data needed to achieve this outcome can now be generated in the laboratory.

\section{Acknowledgement}

This work described herein was conducted as part of the AMIRA International Limited P266 'Improving Thickener Technology' collaborative research projects (stages E, F and G) and supported by the Australian Research Council (ARC) under the Linkage Grants Scheme. The sponsors of these projects are gratefully acknowledged. The authors also acknowledge the support of the Particulate Fluids Processing Centre (PFPC), a Special Research Centre of the ARC, and technical inputs to, advice and operational help by Dr Phillip Fawell (CSIRO), Mr Kosta Simic (CSIRO) and Mr Adam Kilcullen (University of Melbourne).

\section{References}

Auzerais, FM, Jackson, R \& Russel, WB 1990, 'The transient settling of stable and flocculated dispersions', Journal of Fluid Mechanics, vol. 221, pp. 613-639.

Bergstrom, L, Schilling, CH \& Aksay, IA 1992, 'Consolidation behaviour of flocculated alumina suspensions', Journal of the American Ceramic Society, vol. 75, pp. 3305-3314.

Bürger, R, Concha, F \& Karlsen, KH 2001, 'Phenomenological model of filtration processes: 1. Cake formation and expression', Chemical Engineering Science, vol. 56, pp. 4537-4553.

Bürger, R \& Wedland, WL 1998, 'Entropy boundary and jump conditions in the theory of sedimentation with compression', Mathematical Methods in the Applied Sciences, vol. 21, pp. 865-882.

Buscall, R \& White, LR 1987, 'The consolidation of concentrated suspensions', Journal of the Chemical Society, Faraday Transactions 1, vol. 83, pp. 873-891.

Bustos, MC, Concha, F, Burger, R \& Tory, EM 1999, Sedimentation and Thickening, Kluwer Academic Publishers, Dordrecht.

Coe, HS \& Clevenger, GH 1916, 'Methods for determining the capacities of slime settling tanks', AIME Transactions, vol. 55, pp. 356-384.

Comings, EW, Pruiss, CE \& DeBord, C 1954, 'Continuous settling and thickening', Industrial and Engineering Chemistry, vol. 46, pp. 1164-1172.

de Kretser, RG, Usher, SP, Scales, PJ, Boger, DV \& Landman, KA 2001, 'Rapid filtration measurement of dewatering design and optimization parameters', AIChE Journal, vol. 47, no. 8, pp. 1758-1769.

Diehl, S 2000, 'On boundary conditions and solutions for ideal clarifier-thickener units', Chemical Engineering Journal, vol. 80, pp. 119-133.

Farrow, J, Johnston, R, Simic, K \& Swift, J 2000, 'Consolidation and aggregate densification during gravity thickening', Chemical Engineering Journal, vol. 80, pp. 141-148.

Fawell, PD, Farrow, JB, Heath, AR, Nguyen, TV, Owen, AT, Paterson, D, Rudman, M, Scales, PJ, Simic, K, Stephens, DW, Swift, JD, \& Usher, SP 2009, '20 years of AMIRA P266 "Improving Thickener Technology" - how has it changed the understanding of thickener performance?', in RJ Jewell, AB Fourie, S Barrera \& J Wiertz, Proceedings of the 12th International Seminar on Paste and Thickened Tailings, Australian Centre for Geomechanics, Perth, pp. 59-68..

Fitch, B 1966, 'Current theory and thickener design', Industrial and Engineering Chemistry, vol. 58, pp. 18-28.

Fitch, B 1971, 'Batch tests predict thickener performance, Chemical Engineering, 23 August, pp. 83-88. 
Gibson, RE, England, GL \& Hussey, MJL 1967, 'The theory of one dimensional consolidation of saturated clays', Géotechnique, vol. 17, pp. 261-273.

Gladman, B, de Kretser, RG, Rudman, M \& Scales, PJ 2005, 'Effect of shear on particulate suspension dewatering', Chemical Engineering Research \& Design, vol. 83 (A7), pp. 933-936.

Gladman, BR, Rudman, M \& Scales, PJ 2010, 'The effect of shear on gravity thickening: pilot scale modelling', Chemical Engineering Science, vol. 65, issue 14, pp. 4293-4301.

Grassia, P, Zhang, Y, Martin, AD, Usher, SP, Scales, PJ, Crust, A \& Spehar, R 2014, 'Effects of aggregate densification upon thickening of Kynchian suspensions', Chemical Engineering Science, vol. 111, pp. 56-72.

Heath, AR, Bahri, PA, Fawell, PD \& Farrow, JB 2006a, 'Polymer flocculation of calcite: sxperimental results from turbulent pipe flow', AlChE Journal, vol. 52, pp. 1284-1293.

Heath, AR, Bahri, PA, Fawell, PD \& Farrow, JB 2006b, 'Polymer flocculation of calcite: Population balance model', AlChE Journal, vol. 52, pp. 1641-16531.

Howells, I, Landman, KA, Panjkov, A, Sirakoff, C \& White, LR 1990, 'Time dependent batch settling of flocculated suspensions', Applied Mathematical Modelling, vol. 14, pp. 77-86.

Karl, JR 1999, 'Numerical model of sedimentation/thickening with inertial effects', Journal of Environmental Engineering, vol. 125, pp. 792-806.

Kynch, GJ 1952, 'A theory of sedimentation', Transactions of the Faraday Society, vol. 48, pp. 166-176.

Landman, KA, White, LR \& Buscall, R 1988, 'The continuous flow gravity thickener: Steady state behaviour', AIChE Journal, vol. 34, pp. 239-252.

Landman, KA, White, LR \& Eberl, M 1995, 'Pressure filtration of flocculated suspensions', AlChE Journal, vol. 41, pp. 1687-1699.

Lester, DR, Rudman, M \& Scales, PJ 2010, 'Macroscopic dynamics of flocculated colloidal suspensions'. Chemical Engineering Science, vol. 65, no. 24, pp. 6362-6378.

Lester, DR, Usher, SP \& Scales, PJ 2005, 'Estimation of the hindered settling function R(phi) from batch-settling tests'. AlCicheE Journal, vol. 51, no. 4, pp. 1158-1168.

Loan, C \& Arbuthnot, I 2010, 'Innovative technology for optimised thickening sedimentation', Proceedings of the XXV International Mineral Processing Congress, Australasian Institute of Mining and Metallurgy, Melbourne.

Michaels, AS \& Bolger, JC 1962, 'Settling rates and sediment volumes of flocculated kaolin suspensions', I\&EC Fundamentals, vol. 1, no. 1, pp. 24-33.

Owen, AT, Fawell, PD, Swift, JD, Labbett, DM, Benn, FA \& Farrow, JB 2008, 'Using turbulent pipe flow to study the factors affecting polymer-bridging flocculation of mineral systems', International Journal of Mineral Processing, vol. 87, no. 3-4, pp. 90-99.

Rudman, M, Simic, K, Paterson, DA, Strode, P, Brent, A \& Sutalo, ID 2008, 'Raking in gravity thickeners', International Journal of Mineral Processing, vol. 86, no. 1-4, pp. 114-130.

Scott, KJ 1970, 'Continuous thickening of flocculated suspensions. Comparison with batch settling tests and effects of floc compression using pyrophyllite pulp', Industrial and Engineering Chemistry Fundamentals, vol. 9, pp. 422-427.

Sofra, F \& Boger, DV 2002, 'Environmental rheology for waste minimisation in the minerals industry', Chemical Engineering Journal, vol. 86, no. 3, pp. 319-330.

Spehar, R 2014, 'Modelling the role of shear in compressional dewatering', PhD thesis, University of Melbourne, Melbourne.

Spehar, R, Kiviti-Manor, A, Fawell, PD, Usher, SP, Rudman, M \& Scales, PJ 2015, 'Aggregate densification in the thickening of flocculated suspensions in an un-networked bed', Chemical Engineering Science, vol. 122, 585-595.

Stickland, AD, de Kretser, RG, Kilcullen, AR, Scales, PJ, Hillis, P \& Tillotson, MR 2008, 'Numerical Modeling of flexible-membrane plate-and-frame filtration', AIChE Journal, vol. 54, no. 2, pp. 464-474.

Usher, SP, de Kretser, RG \& Scales, PJ 2001, 'Validation of a new filtration technique for dewaterability characterization', AlChE Journal, vol. 47, no. 7, pp. 1561-1570.

Usher, SP \& Scales, PJ 2005, 'Steady state thickener modelling from the compressive yield stress and hindered settling function', Chemical Engineering Journal, vol. 111, no. 2-3, pp. 253-261.

Usher, SP \& Scales, PJ 2009, 'Predicting settler/clarifier behaviour: the role of shear effects,' Filtration, vol. 9, pp. 308-314.

Usher, SP, Spehar, R \& Scales, PJ 2009, 'Theoretical analysis of aggregate densification: impact on thickener performance', Chemical Engineering Journal, vol. 151, pp. 202-208.

van Deventer, BBG, Usher, SP, Kumar, A, Rudman, M \& Scales, PJ 2011, 'Aggregate densification and batch settling', Chemical Engineering Journal, vol. 171, no. 1, pp. 141-151.

Vesilind, PA \& Jones, GN 1993, 'Channelling in batch thickening', Water Science and Technology, vol. 28, pp. 59-65.

Zhang, Y, Grassia, P \& Martin, AD 2013, 'Prediction of thickener performance with aggregate densification', Chemical Engineering Science, vol. 101, pp. 346-358. 